\title{
CFD Analysis of Manipulator Cabin by Selecting Proper Air Conditioning System
}

\author{
Umesh S. Ghorpade ${ }^{1^{*}}$, Manik A. Patil ${ }^{\text {*** }}$,Amit S. Shelake ${ }^{3 * *}$, \\ Himanshu S. Ghodake ${ }^{4 * *}$ \\ ${ }^{1}$ Assistant Professor, Sanjeevan Engineering \& Technology Institute, Panhala, India \\ ${ }^{2}$ Assistant Professor, Sanjeevan Engineering \& Technology Institute, Panhala, India \\ ${ }^{3}$ Assistant Professor, Sanjeevan Engineering \& Technology Institute, Panhala, India \\ ${ }^{4}$ Student, Sanjeevan Engineering \& Technology Institute, Panhala, India
}

\begin{abstract}
Manipulator is a machine which is used to transfer heavy objects, to reduce human efforts in many industrial applications. Some of them are fully automated while some are manually operated. It is difficult to work in cabin of manipulator for the operator under hot conditions. So it is es sential to provide co mfort to operator using air-conditioning system. For such applications standard air conditioners are not compatible, so we have to develop assembled system. In this paper we will be dealing with design, selection and fabrication of components like co mpres sor, condenser, expansion device and evaporator. In order to do so, we have calculated heat load .

Keywords: Heat load, Compressor, heat transfer coefficient, CFD.
\end{abstract}

\section{INTRODUCTION}

Air conditioning is concerned with the absorption of heat from where it is objectionable plus its transfer to and rejection at a place where it is unobjectionable and keeps the place comfortable for occupants. Air conditioning comprises maintaining temperature, humidity level, noise control, cleanliness. There are so many methods of air conditioning; according to situation a particular system is adopted. Usually after estimating the load standard manufactured unit is installed. Regardless of availability of various systems we need to develop a system fitting to the specific application due to co-occurrence of multiple factor affecting the system. As the environment of casting industry is hot, dusty, noisy, affecting the efficiency of workers. Now days casting industries are automated industries. They have fully mechanized conveyors for transportation of hot casting to the fettling section. To place casting from vibrator to conveyor manually operated manipulators are used. The working condition for the operator is largely influenced by the temperature and dust of castings. The outer temperature is around $50^{\circ} \mathrm{C}$ during working hours. The manipulator is not equipped with the air conditioning facility; so it's not comfortable to the operator. The cabin of manipulator is so compact that only a person can fit in it and hence can't be equipped with standard AC system. Even we apply standard system; cabin vibrations with high amplitude causes system to fail due to unsuitable mounting. So we have developed an air conditioning system which maintains temperature, humidity level, noise control and cleanliness.

\section{CALCUlation}

Calculations are required to determine the total load inside the manipulator cabin. The dimensions of the manipulator cabin are shown in the Fig. 1.

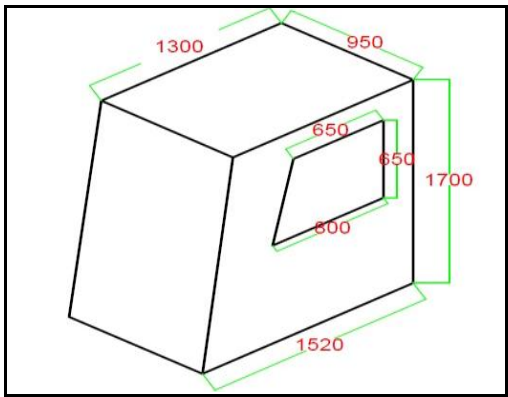

Figure 1.Manipulator Cab in

\section{He at Load calcul ation.}

- Indoor condition: $25^{\circ} \mathrm{C}$, with RH $25 \%$ - $70 \%$ and selected $60 \%$,

Therefore $25^{\circ} \mathrm{DBT}$ and $60 \% \mathrm{RH}$ selected.

- Outdoor condition: $50^{\circ} \mathrm{C}$, with RH $30 \%-40 \%$. We will consider $42^{\circ} \mathrm{C}$ as the maximu m limit on psychrometric chart.

- Volume of cabin:

Area $1=\mathrm{A} 1=1.7 \times 1.3=2.21 \mathrm{~m}^{2} ;$ Area $2=\mathrm{A} 2=$ $0.22 \times 1.7 \times 0.8=2.27 \mathrm{~m}^{2}$

Therefore, Total Area: $\mathrm{A}=\mathrm{A} 1+\mathrm{A} 2=2.27+0.187$ $=2.457 \mathrm{~m}^{2}$

Volu me, $\mathrm{V}=2.457 \times 0.950=2.3341 \mathrm{~m}^{3}$

- Thermal conductivities: 
For fiber glass, $\mathrm{k}=0.04 \mathrm{~W} / \mathrm{m}-\mathrm{K}$; for steel, $\mathrm{k}=$ $43 \mathrm{~W} / \mathrm{m}-\mathrm{K}$

- Heat transfer coefficient: Between air and glass, $\mathrm{h}=25 \mathrm{~W} / \mathrm{m}^{2}-\mathrm{K}$

- $\quad$ Sensible heat and Latent heat; At $25^{\circ} \mathrm{C}$ i.e. $78^{\circ} \mathrm{F}$ seated very light work,

Sensible heat $=215 \mathrm{BTU} / \mathrm{hr}=62.995=63 \mathrm{~W}$ and

Latent heat $=185 \mathrm{BTU} / \mathrm{hr}=54.25=54 \mathrm{~W}$

- Overall heat transfer coefficient for g lass $\mathrm{U}$ : $U=\frac{1}{\frac{1}{25}+\frac{0.005}{0.04}+\frac{1}{25}}$

Hence, $\mathrm{U}=4.88 \mathrm{~W} / \mathrm{m}^{2}-\mathrm{K}$

- Heat estimation:

$\mathrm{Q}=\mathrm{UADT}=4.88^{*}(50-25) * \mathrm{~A}$

Through front glass window, $\mathrm{Q}_{\mathrm{f}}=4.88 \times 25 \times$

$(1.615 \times 1 / \sin 83)=198.51 \mathrm{~W}$

Through side doors, $\mathrm{Qs}=2 * \mathrm{Qs}_{1}$

And $\mathrm{Qs}_{1}=\mathrm{Q}_{\mathrm{g}}+\mathrm{Q}_{\text {steel }}$

$\mathrm{Qg}=\mathrm{UADT}=4.88 \times[(0.65 \times 0.850)+$

$(0.5 \times 150 \times 0.001 \times 0.850)] \times 25=75.152 \mathrm{~W}$

- Overall heat transfer coefficient for steel and glass interface U; For glass,

$$
U_{g}=\frac{1}{\frac{1}{25}+\frac{0.01}{48}+\frac{1}{25}}=12.46 \mathrm{~W} / \mathrm{m}^{2}-\mathrm{K}
$$

For steel: From MS steel Eng ineering Tool box we get, Ust $=7.9$ i.e. 8 Appr.

- Heat estimation

Area As $=(2.397-0.616)=1.781 \mathrm{~m}^{2}$

$\mathrm{Q}$ for steel, Qst $=8 \times 1.781 \times 25=356.2 \mathrm{~W}$.

Therefore, $\mathrm{Qs}_{1}=75.152+356.2=431.352 \mathrm{~W}$

And Qs $=2 *$ Qs $1=2 \times 431.352=862.74 \mathrm{~W}$. (10)

- Through the rear side there is negligible heat gain due to various outer equipments mounting and noise reducing coating layer.

- Occupancy Load:

The heat emitted from the bodies of the people also constitutes a major portion of a summer cooling load. The heat quantities given up by the occupants are dependent on activity of the persons, sex, age and indoor dry bulb temperature. From Standard table,

Latent heat $=54 \mathrm{~W}$ and Sensible heat $=63 \mathrm{~W}$

Therefore, Total occupancy load Qo $=117 \mathrm{~W}$. (11)

- Other loads;

For other heat source $10 \%$ to $15 \%$ of total heat load is taken.

- Fresh air load estimation:

Air change per hour $=2$, considering office private and no smoking.

Taking outside air $0.75 \mathrm{~m} 3 / \mathrm{min}$-pers on

Therefore, Fresh air load $=3 \times 2=6 \mathrm{~m}^{3} / \mathrm{hr}$.

- Infiltration load :
For infiltration load considering $10 \%$ of the total load

- Total heat :

$\mathrm{Q}_{\text {total }}=\mathrm{Q}_{\mathrm{f}}+\mathrm{Qs}+\mathrm{Qo}=198.51+862.70+117$

$=1178.214 \mathrm{~W}$

- $\quad$ Load due to light and equipment load :

Considering light load and equipment load as $20 \%$ of total heat load i.e.,

Light load and equipment load $=20 \% \mathrm{Q}_{\text {total }}=$ $0.2 \times 1178.214=235.64 \mathrm{~W}$.

- On Psychrometric Chart :

Following points were plotted,

A] $42^{\circ} \mathrm{C}$ - DBT, $\left.40 \% \mathrm{RH}, \quad \mathrm{B}\right] 25^{\circ} \mathrm{C}$ - DBT, 60 $\% \mathrm{RH}$,

Specific volu me of air at 1 ,

$\mathrm{Vs}_{1}=0.92+8 \times 10-4 \times 3=0.9224 \mathrm{~m} 3 / \mathrm{kg}$

Infiltrated air at point $1=20 \%(\mathrm{Vol}) / \mathrm{hr}=0.2 \times 3 / 60$ $=0.02 \mathrm{~m}^{3} / \mathrm{min}$.

Mass, $\mathrm{ma}=0.01=0.0108 \mathrm{Kg} / \mathrm{min}$

Fresh air $=2 \times \mathrm{V}=2 \times 3=6 \mathrm{~m}^{3} / \mathrm{hr}$

i.e. equal to $0.1 \mathrm{~m}^{3} / \mathrm{min}$

Enthalpy at 1 i.e. $\mathrm{h} 1=97.5 \mathrm{KJ} / \mathrm{Kg}$ of dry air,

Enthalpy at 2 i.e. $\mathrm{h} 2=56 \mathrm{KJ} / \mathrm{Kg}$ of dry air,

Enthalpy at $\mathrm{A}$ i.e. $\mathrm{h}_{\mathrm{A}}=74 \mathrm{KJ} / \mathrm{Kg}$ of dry air.

- Heat due to infiltration:

i. Sensible heat gain due to infiltration air $=\mathrm{ma}$ (ha-h2) $=0.0108(74-56)$

$=0.1944 \mathrm{KJ} / \mathrm{min}$ i.e. equal to $3.24 \mathrm{~W}$.

ii. Latent heat due to infiltration air $=$ ma $(\mathrm{h} 1-\mathrm{hA})$ $=0.0108(97.5-74)$ $=0.2538 \mathrm{KJ} / \mathrm{min}$ i.e. equal to $4.23 \mathrm{~W}$.

- Total latent heat gain in room, $\mathrm{RLH}=4.23+54$ $=58.23 \mathrm{~W}$.

- Total sensible heat gain in room, $\mathrm{RSH}=$ $3.24+63+235.64+117.214=1480.004$.

- Room sensible heat factor, $\mathrm{RSHF}=(\mathrm{RSH} / \mathrm{RSH})+\mathrm{RLH}=$ $(1480.094 / 1480.094)+58.23=0.9621$.

- Alignment Circle: Align ment circle points are, (20\% DBT, 50\% RH)

Suppose for $70 \%$ return air and 30\% fresh air then by trial and error method drawing line fro $\mathrm{m} 30$ to 15 on saturation curve we get,

a) Bypass factor $=0.157$, b) $\operatorname{td} 3=28.2^{\circ} \mathrm{C} \quad$ c) $\operatorname{td} 4$ $\left.=17.5^{\circ} \mathrm{C} \mathrm{d}\right) \operatorname{td} 6=15.5^{\circ} \mathrm{C}$

Enthalpy at point $4=47.3 \mathrm{KJ} / \mathrm{Kg}$ of air; Enthalpy at point $3=63 \mathrm{KJ} / \mathrm{Kg}$ of air

- Mass entering room: Mass entering room, ma $=\mathrm{RSH}+\mathrm{RLH}=1480.09+58.23$

Therefore, $\mathrm{ma}=0.1768 \mathrm{Kg} / \mathrm{s}=10.61 \mathrm{~kg} / \mathrm{min}$

(21)

Capacity of plant $=$ ma $(\mathrm{h} 3-\mathrm{h} 4)$

Therefore, Capacity of plant $=10.61(63-47.3)=$ $166.577 \mathrm{KJ} / \mathrm{min}=0.793 \mathrm{TR}$

- Total load; Assuming factor of safety i.e. F.S $=1.25$

Hence, Total Load $=$ Capacity of plant $\times$ F.S $=$ $0.793 \times 1.25=0.9875 \approx \mathbf{1}$ TR. 


\section{CFD analys is}

The Analysis of Manipulator cabin is carried out using Ansys 14.0 software. This process consists of Three Primary Steps:

3.1 Pre-Processing:- This is the first step of CFD simulation process which helps in describing the geometry in the best possible manner. One needs to identify the fluid domain of interest.

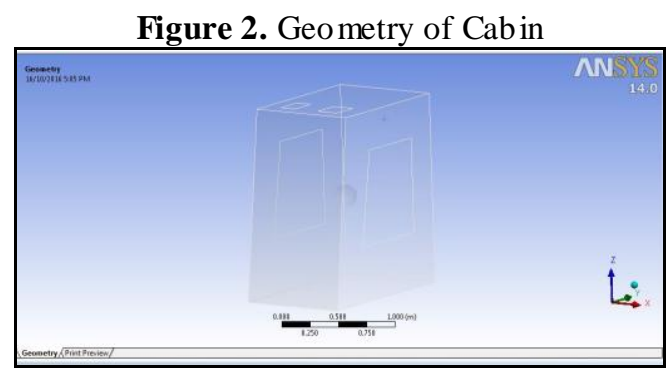

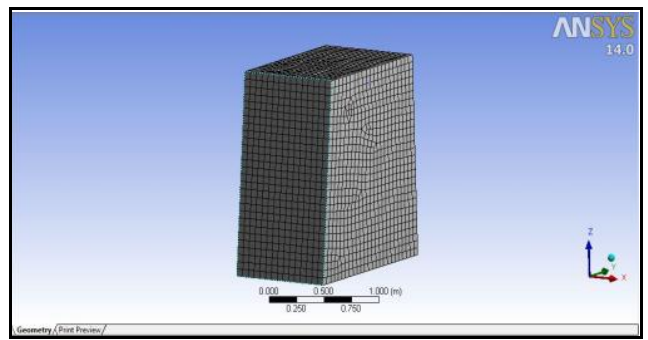

Figure 3. Meshing of Cabin

3.2 Solver: - Once the problem physics has been identified, fluid material properties, flow physics model, and boundary conditions are set to solve using a computer.

- Indoor condition: $25^{\circ} \mathrm{C}$

- Outdoor condition: $50^{\circ} \mathrm{C}$.

- Capacity of air conditioner:1 TR

3.3 Post-Processing:- The next step after getting the results is to analyze the results with different methods like contour plots, vector plot, streamlines, data curve etc. for appropriate graphical representations and report.

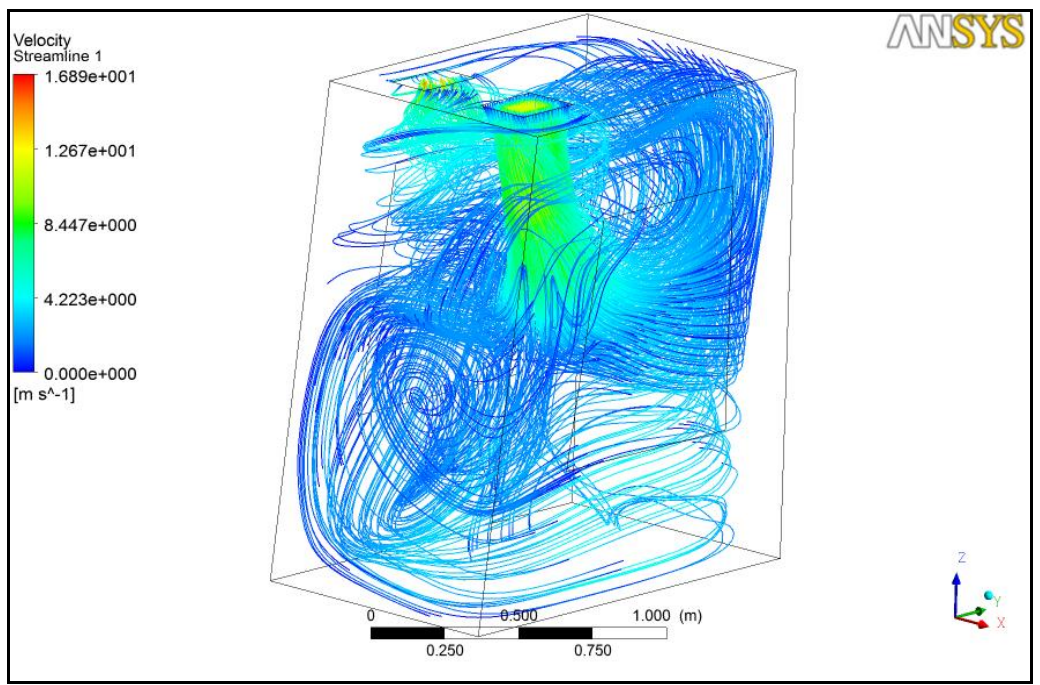

Figure 4. Velocity Streamlines

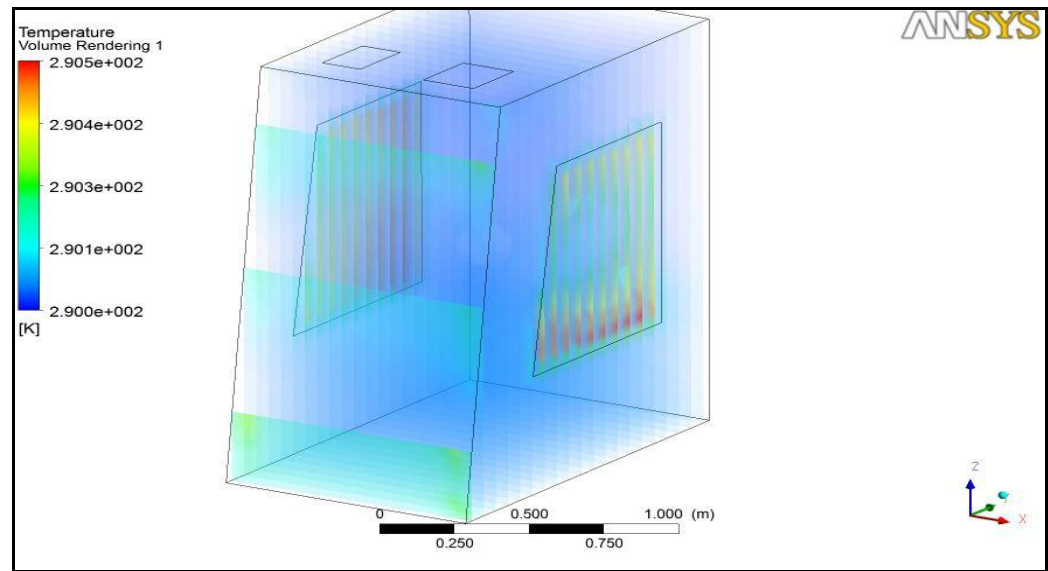

Figure 5. Temperature Velocity Rendering 


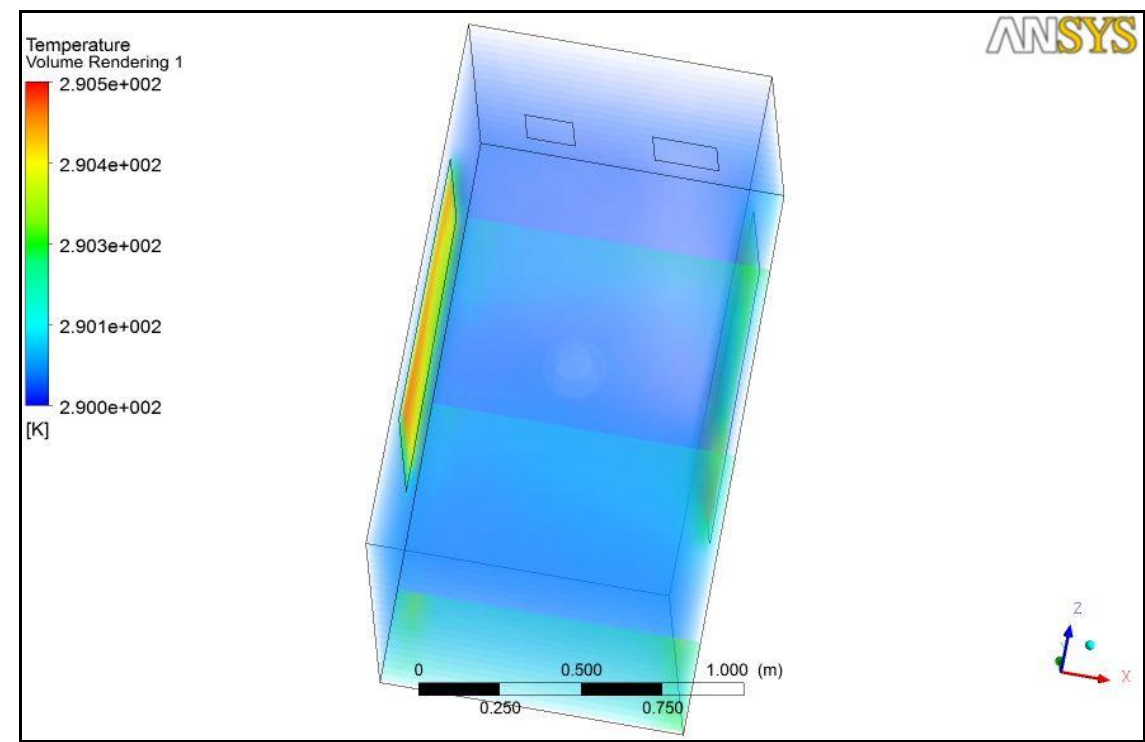

Figure 6. Temperature Volu me Rendering

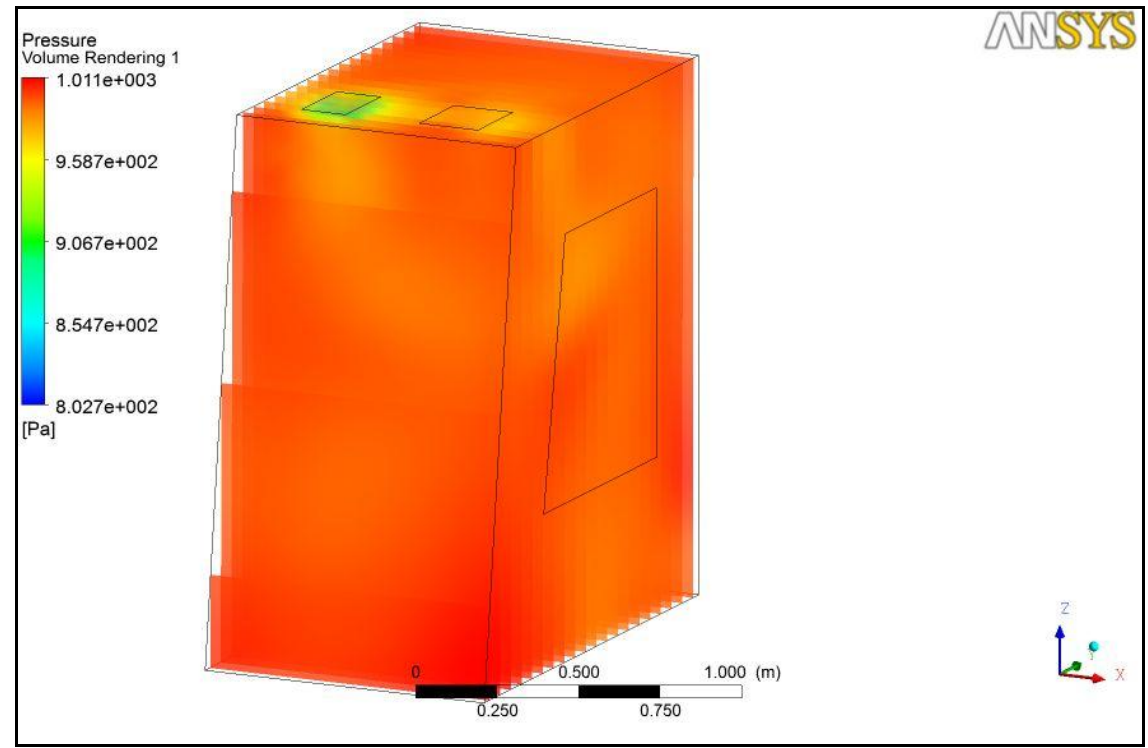

Figure 7. Pressure Volu me Rendering

\section{CONCLUSION}

By the study of heat load estimation formulae's, some considerations and from the basic laws of thermodynamics the total heat load is calculated as $1 \mathrm{TR}$.

From the temperature volume rendering diagram and temperature velocity rendering diagram we conclude that the temperature distribution inside the cabin is uniform and is under comfort zone.

\section{REFERENCES}

[1] Liu Sheng jun et.al, "Thermodynamic analysis of actual air cycle refrigeration system", System Engineering, Procedial (2011) 112-116.

[2] K. Nagalakshmi et.al, "The design and performance analysis of refrigeration system using R-12 and R134a refrigerants", ISSN: 2248-9622. VOL. Issue 2(Version 1), February 2014, pp.638-643.

[3] Xing Xue et.al, "Modeling and simulation of an air cooling condenser under transient conditions", Procedia Engineering 31 (2012) 817-822.

[4] T. S. Jadhav, "Theoretical energy saving analysis of air conditioning system using heat pipe for Indian climatic zones", Engineering Science and Technology, Journal (15)669-673.

[5] Xu Song et.al, "Cooling and dehumidification capacity chart of surface air cooler in air conditioning", Procedia Engineering 121 (2015) 2014-2020. 
[6] A. V. Domkundwar, "Refrigeration and Air Conditioning", DhanpatRai Publishing House Pvt. Ltd. Reprint 2011 ISBN 978-817700-000-9.

[7] Abdullah A. A. a. Al-Rashid "Effect of evaporator temperature on vapour compression refrigeration system", Alexandria Engineering Journal (2011) 50, 283-290

[8] Isacco Stiaccini et.al "A hybrid timefrequency approach for numerical modeling of reciprocating compressors" Procedia Engineering 31 (2012) 817-822

[9] Liu Jing1, PEI Qing-quing2 "Numerical Simulation And Experimental Study of Indoors Thermal Environment in Summer Air-Conditioned Room" Procedia Engineering 52 (2013) 230-235

[10] Qi Cheng et.al. "Robust optimal design of chiller plants based on cooling load distribution" Energy Procedia 75 (2015) 1354-1359

[11] R.K.Rajput "Air conditioning and refrigeration" Eurasia Publishing House (P).Ltd Reprint, 2015, ISBN 978-81-212781-9. 